\title{
METODOLOGIAS QUE PERMEIAM A EDUCAÇÃO \\ PROFISSIONAL E TECNOLÓGICA A PARTIR DE UM ESTADO DA \\ ARTE
}

\author{
METHODOLOGIES THAT ALLOW PROFESSIONAL AND \\ TECHNOLOGICAL EDUCATION FROM AN ART STATE
}

\author{
Emerson Carlos da Silva ${ }^{7}$ \\ Marcos Sérgio Carvalho Rebouças ${ }^{8}$ \\ Aleksandre Saraiva Dantas ${ }^{9}$ \\ Diogo Pereira Bezerra ${ }^{10}$
}

A dinâmica da contemporaneidade e a rapidez das transformações no mundo do trabalho e das práticas sociais têm desafiado as instituições de ensino a buscarem práticas e metodologias alternativas, que proporcionem eficácia e eficiência na arte do aprender. Isso se desdobra tanto na educação propedêutica quanto na Educação Profissional e Tecnológica (EPT), que é objeto de estudo desse artigo e se apresenta como alvo de disputa política, econômica e ideológica.

Esse tipo de educação, ora é entendido como uma vertente que deve estar intimamente ligada à educação propedêutica, ora como ícone, simplesmente, de complementação ou como método alternativo para essa, sendo esse pressuposto um entendimento visível nas legislações que regem esse tema (RAMOS, 2014). É importante

\footnotetext{
${ }^{7}$ Licenciado em Matemática (UERN), discente do Mestrado Profissional em Educação Profissional e Tecnológica - PROFEPT/IFRN. E-mail: emersoncarlos90@ hotmail.com

${ }^{8}$ Bacharel em Engenharia de Produção (UFERSA) e discente do Mestrado Profissional em Educação Profissional e Tecnológica - PROFEPT/IFRN. E-mail:marcossergio10@ hotmail.com

${ }^{9}$ Licenciado em Matemática (UERN) Especialista em Educação (UERN); Especialista em Ensino de Matemática para o Ensino Médio (IFRN); Mestre em Engenharia de Produção (UFSC); Mestre em Matemática (UFERSA); Doutor em Educação (UFRN). Professor Titular do Instituto Federal de Educação Ciência e Tecnologia do Rio Grande do Norte (IFRN)/Campus de Mossoró. E-mail: aleksandre.dantas@ifrn.edu.br

${ }^{10}$ Licenciado em Química (UECE); Mestre em Engenharia Química (UFC); Doutor em Engenharia Química (UFC). Professor Titular do Instituto Federal do Rio Grande do Norte - IFRN - Campus de Ipanguaçu. E-mail: diogoquantum@gmail.com.
} 
salientar que o processo de implementação da EPT é alvo de diversos estudos e pesquisas investigativas que estudam e analisam suas implicações, causas e consequências na formação do sujeito.

A partir da preocupação com quais metodologias estão sendo utilizadas no ensino em EPT, ou mesmo se há metodologias específicas voltadas a essa modalidade de ensino, buscase, nesta pesquisa, realizar um levantamento das metodologias utilizadas nesse campo, mas especificamente, no âmbito do Ensino Médio e suas modalidades em EPT, baseada em um Estado da Arte, sendo uma pesquisa de cunho qualitativo e abordagem bibliográfica, ainda, buscando o diálogo dessas metodologias com o entendimento de autores como Maria Ciavatta (2014), Mário Manacorda (2007), Marise Ramos (2014), Dante Moura (2015) entre outros.

A sequência deste artigo está estruturada: primeiramente, um Estado da Arte sobre as metodologias de ensino utilizadas na EPT, onde se busca realizar um levantamento sobre quais metodologias estão sendo utilizadas na EPT no período de 2010 a 2020; em seguida, aborda-se a EPT na perspectiva da formação do Ensino Médio Integrado, a partir de uma breve discussão da importância do trabalho na formação do cidadão; no terceiro item, enfatiza-se as Metodologias Ativas como alternativa desse processo; no quarto item, apresenta-se uma discussão sobre essas metodologias e os entendimentos das bases conceituais em EPT, a partir de alguns teóricos; por fim, há as considerações finais.

\section{Um estado da arte sobre metodologias utilizadas na EPT}

Este trabalho surge da seguinte problemática: quais metodologias de ensino estão sendo utilizadas na EPT, no âmbito do Ensino Médio? Existem metodologias de ensino específicas para essa modalidade educacional?

Sem a pretensão de esgotar essa discussão, mas buscando oferecer uma contribuição para esse debate, realizou-se uma pesquisa de cunho qualitativo, tendo em vista essa pautar-se no estudo e na análise do mundo empírico (GODOY, 1995), com abordagem bibliográfica, pois essa é desenvolvida com base em material já produzido, composto por livros, artigos científicos, mas ainda, por essa técnica proporcionar uma cobertura ampla de materiais (GIL, 2008). 
Como suporte para o levantamento de materiais, utilizou-se o Estado da Arte, sendo que a escolha dessa ferramenta se deu devido às possibilidades de reconhecimento ou mapeamento de estudos que estão sendo realizados em uma localidade e em dado recorte temporal.

De acordo com Ferreira (2002), sobre o Estado da Arte, tem-se:

Definidas como de caráter bibliográfico, elas parecem trazer em comum o desafio de mapear e de discutir uma certa produção acadêmica em diferentes campos do conhecimento, tentando responder que aspectos e dimensões vêm sendo destacados e privilegiados em diferentes épocas e lugares, de que formas e em que condições têm sido produzidas certas dissertações de mestrado, teses de doutorado, publicações em periódicos e comunicações em anais de congressos e de seminários. Também são reconhecidas por realizarem uma metodologia de caráter inventariante e descritivo da produção acadêmica e científica sobre o tema que busca investigar, à luz de categorias e facetas que se caracterizam enquanto tais em cada trabalho e no conjunto deles, sob os quais o fenômeno passa a ser analisado (FERREIRA, 2002, p. 02).

Tendo essa formulação, observa-se a potencialidade que um Estado da Arte proporciona em diversos tipos de pesquisa, embasando, assim, a sua escolha para este artigo. Essa ferramenta foi utilizada com o intuito de elencar as metodologias de ensino que estão sendo utilizadas na EPT, na perspectiva do Ensino Médio. Para tanto, utilizou-se um recorte temporal de 2010 a 2020.

As buscas foram realizadas através da plataforma Google Acadêmico (Google Scholar), utilizando os filtros da própria plataforma. Inicialmente, foi feita uma busca com o descritor "metodologias de ensino na educação profissional e tecnológica", ou seja, a partir da frase exatamente como se apresenta, e nenhum resultado foi encontrado. Já com o filtro "no mínimo uma das palavras" pertencente ao descritor utilizado, foram encontrados 680.000 resultados.

Quando a busca foi realizada a partir de todas as palavras do descritor "metodologias de ensino na educação profissional", foram adquiridos 15.100 resultados. Com o descritor "metodologias de ensino para a educação profissional", obteve-se 14.800 resultados. Para a descrição "metodologias de ensino para EPT", tivemos 4.520 resultados. Através do descritor "metodologias de ensino para EPT", com as palavras "metodologias" e "EPT" entre aspas, o que especifica melhor o conteúdo da busca, foram expostos 2.620 resultados, dos quais 
seriam averiguados apenas artigos científicos, tendo em vista a grande quantidade de trabalhos apresentados pela plataforma e o delineamento da investigação.

Com isso, passou-se a analisar os títulos de cada artigo a fim de verificar os que se aproximavam do tema proposto. Dentre esses, 34 artigos foram evidenciados por aproximação do título ao tema, possuindo certa correlação, ou seja, trabalhos que estavam relacionados a metodologias no ensino de forma geral, mas nem todos ligados a EPT.

Passando-se a leitura dos resumos desses artigos, finalizou-se o processo com 10 artigos alinhados às metodologias de ensino para EPT no âmbito do Ensino Médio. Estes encontram-se sinteticamente descritos no quadro 1 . Os 24 artigos descartados tratavam de metodologias em outros níveis de ensino, voltados, por exemplo, para o Ensino Superior.

Iniciou-se, assim, a análise dos que discorriam sobre o foco da pesquisa, ou seja, sobre as metodologias utilizadas na EPT.

Quadro 1- Artigos alinhados ao tema desta pesquisa que foram analisados

\begin{tabular}{|c|c|c|c|}
\hline ANO & TÍTULO & AUTORES & ASSUNTO \\
\hline 2019 & $\begin{array}{l}\text { Aprendizagem Baseada em } \\
\text { Problemas como Metodologia } \\
\text { Ativa na Educação Profissional. }\end{array}$ & $\begin{array}{l}\text { KLEIN, Niumar } \\
\text { André; AHLERT, } \\
\text { Edson Moacir. }\end{array}$ & $\begin{array}{l}\text { Apresenta a proposta de metodologia ativa de } \\
\text { Aprendizagem Baseada em Problemas (PBL) para } \\
\text { o desenvolvimento de uma atividade, dita } \\
\text { situação-problema, alinhada ao contexto de } \\
\text { formação profissional técnica dos alunos, em um } \\
\text { curso Técnico em Eletroeletrônica e Automação } \\
\text { Industrial. }\end{array}$ \\
\hline 2016 & $\begin{array}{l}\text { Prática pedagógica baseada em } \\
\text { Metodologia } \\
\text { aprendizagem sob ativa: } \\
\text { perspectiva do letramento } \\
\text { informacional para o ensino na } \\
\text { Educação Profissional. }\end{array}$ & $\begin{array}{l}\text { MOREIRA, } \\
\text { Jonathan Rosa; } \\
\text { RIBEIRO, } \\
\text { Jefferson Bruno } \\
\text { Pereira. }\end{array}$ & $\begin{array}{l}\text { Traz a metodologia ativa através da } \\
\text { Aprendizagem Baseada em Ensino e Pesquisa } \\
\text { (ABEP), sendo essa uma variação da metodologia } \\
\text { baseada em problemas, em um curso Técnico em } \\
\text { Informática para Internet. }\end{array}$ \\
\hline 2014 & $\begin{array}{l}\text { Dinâmicas de grupo orientadas } \\
\text { pelas atividades de estudo: } \\
\text { desenvolvimento de } \\
\text { habilidades e competências na } \\
\text { Educação Profissional. }\end{array}$ & $\begin{array}{l}\text { ALBERTI, } \\
\text { Fim et al. }\end{array}$ & $\begin{array}{l}\text { Suscita as dinâmicas de grupo e sua contribuição } \\
\text { para aquisição de conhecimentos teórico- } \\
\text { práticos, em um curso Técnico em Administração } \\
\text { de Empresas. }\end{array}$ \\
\hline 2019 & profissional, & MACHADO, & Faz um estudo sobre a gamificação como uma \\
\hline
\end{tabular}




\begin{tabular}{|c|c|c|c|}
\hline & $\begin{array}{l}\text { gamificação e Educação } \\
\text { Profissional e Tecnológica: uma } \\
\text { revisão sistemática de } \\
\text { literatura. }\end{array}$ & $\begin{array}{l}\text { Yane Ferreira; } \\
\text { OLIVEIRA, } \\
\text { Francisco } \\
\text { Kelsen de. }\end{array}$ & $\begin{array}{l}\text { possibilidade de trabalho, inclusive no campo da } \\
\text { Educação Profissional e Tecnológica, onde realiza } \\
\text { uma revisão sistemática sobre essa metodologia } \\
\text { em diferentes propostas. }\end{array}$ \\
\hline 2018 & $\begin{array}{l}\text { Metodologias ativas na } \\
\text { Educação Profissional e } \\
\text { Tecnológica. }\end{array}$ & $\begin{array}{l}\text { BARBOSA, } \\
\text { Eduardo } \\
\text { Fernandes; } \\
\text { MOURA, Dácio } \\
\text { Guimarães de. }\end{array}$ & $\begin{array}{l}\text { Faz uma defesa da utilização de Metodologias } \\
\text { Ativas para mediação de conteúdo, juntamente } \\
\text { com a utilização de ferramentas tecnológicas } \\
\text { para o ensino em EPT. }\end{array}$ \\
\hline 2016 & $\begin{array}{l}\text { Metodologias ativas de ensino } \\
\text { na sala de aula: um olhar de } \\
\text { docentes da educação } \\
\text { profissional técnica de nível } \\
\text { médio. }\end{array}$ & $\begin{array}{l}\text { DIESEL, Aline; } \\
\text { ROOS } \\
\text { MARCHESAN, } \\
\text { Michele; } \\
\text { MARTINS, } \\
\text { Silvana } \\
\text { Neumann. }\end{array}$ & $\begin{array}{l}\text { Apresenta as potencialidades da utilização de } \\
\text { Metodologias Ativas em sala de aula, através da } \\
\text { visão de professores de cursos técnicos. }\end{array}$ \\
\hline 2019 & $\begin{array}{l}\text { Metodologias ativas e a } \\
\text { Educação Profissional e } \\
\text { Tecnológica: invertendo a sala } \\
\text { de aula em vista de uma } \\
\text { aprendizagem significativa. }\end{array}$ & $\begin{array}{l}\text { ANDRADE, Luís } \\
\text { Gustavo da } \\
\text { Silva Bispo; } \\
\text { FERRETE, } \\
\text { Rodrigo Bozi. }\end{array}$ & $\begin{array}{l}\text { Versa sobre a importância das Metodologias } \\
\text { Ativas de aprendizagem, especificamente a sala } \\
\text { de aula invertida, e a defesa da utilização das } \\
\text { tecnologias digitais da informação e } \\
\text { comunicação. }\end{array}$ \\
\hline 2013 & $\begin{array}{l}\text { Metodologias ativas de } \\
\text { aprendizagem na Educação } \\
\text { Profissional e Tecnológica. }\end{array}$ & $\begin{array}{l}\text { BELLA, S. R. et } \\
\text { al. }\end{array}$ & $\begin{array}{l}\text { Foca especialmente nas metodologias de } \\
\text { Aprendizagem Baseada em Problemas e } \\
\text { Aprendizagem Baseada em Projetos, vertentes } \\
\text { da Metodologia Ativa, proposta para ensino } \\
\text { técnico. }\end{array}$ \\
\hline 2016 & $\begin{array}{l}\text { O uso de Metodologias Ativas } \\
\text { como ferramenta de } \\
\text { potencialização da } \\
\text { aprendizagem de Diagramas de } \\
\text { Caso de Uso. }\end{array}$ & $\begin{array}{l}\text { PEIXOTO, } \\
\text { Anderson } \\
\text { Gomes. }\end{array}$ & $\begin{array}{l}\text { Propõe um projeto interventivo com a utilização } \\
\text { de Metodologias Ativas, conjuntamente a } \\
\text { metodologias tradicionais, no ensino do } \\
\text { conteúdo Diagramas de Caso de Uso que } \\
\text { pertence à área de engenharia de software, em } \\
\text { um curso Técnico em Informática. }\end{array}$ \\
\hline 2014 & $\begin{array}{l}\text { O uso das TIC's na formação } \\
\text { para o trabalho: um estudo de } \\
\text { caso numa instituição de } \\
\text { Educação Profissional e } \\
\text { Tecnológica. }\end{array}$ & $\begin{array}{l}\text { Marques, C.L; } \\
\text { Souza, A. M. }\end{array}$ & $\begin{array}{l}\text { Analisa as percepções de professores e alunos, } \\
\text { em um Instituto Federal, sobre as } \\
\text { potencialidades de metodologias através de TIC. }\end{array}$ \\
\hline
\end{tabular}


Fonte: Elaborado pelos autores

Percebe-se, com essa análise, as buscas e propostas contínuas por metodologias que se enquadrem, da melhor forma possível, às percepções das práticas de ensinoaprendizagem voltadas à Educação Profissional. Como visto, não há uma uniformidade quanto à utilização de alguma metodologia específica para essa área, considerando os filtros da pesquisa.

Porém, apesar de se encontrar tipos de propostas distintas quanto à implementação dessas metodologias, percebe-se a presença maciça da utilização de Metodologias Ativas e a implementação das Tecnologias Digitais de Informação e Comunicação (TDICs) no Ensino Médio, em suas modalidades com EPT.

Entendemos que as propostas encontradas através da análise não são as únicas, nem exclusivas, para o ensino em EPT. Mesmo havendo diversos outros métodos para a EPT, a pesquisa mostrou a busca crescente por essas metodologias inovadoras.

\section{A EPT NA PERSPECTIVA DA FORMAÇÃO NO ENSINO MÉDIO INTEGRADO}

A EPT passa a ser reconhecida como modalidade de ensino nos anos de 1990, que foi cenário de constantes e rápidas transformações tecnológicas no campo educacional, tendo obtido incentivo das políticas públicas que impulsionaram o seu considerável processo de expansão, nos últimos anos. Desse crescimento, surgem diversas discussões sobre a formação dos sujeitos.

Os sistemas de formação são temas bastante recorrentes em debates no meio político-educacional, ainda mais, sendo essa questão educacional uma ferramenta de poder e controle sobre as classes sociais emergentes, ou seja, dependentes das elites dominantes.

Em uma sociedade capitalista e a margem de uma sociedade justa e igualitária como a brasileira (MOURA; LIMA FILHO; SILVA, 2015), torna-se urgente a discussão da formação 
numa perspectiva com foco na integralidade, omnilateralidade, politecnia, elencados numa visão marxiana de trabalho e educação.

Esses conceitos devem ser internalizados e servem de guias para as práticas de ensino e aprendizagem, principalmente, na perspectiva do Ensino Médio Integrado, tendo em vista o grau de proximidade existente entre educação básica e trabalho, nessa modalidade. A formação nessa unidade deve ser pensada para além de um desenvolvimento fragmentário, simplesmente como adestramento para o mundo do trabalho, daí a importância de se guiar por esses conceitos.

[...] é, portanto, a chegada histórica do homem a uma totalidade de capacidades produtivas e, ao mesmo tempo, a uma totalidade de capacidades de consumo e prazeres, em que se deve considerar sobretudo o gozo daqueles bens espirituais, além dos materiais, e dos quais o trabalhador tem estado excluído em conseqüência da divisão do trabalho (MANACORDA, 2007, p. 89).

A junção entre educação e trabalho tende a ser um contraponto de uma educação unilateral, caso o ensino nessa perspectiva instigue sua materialização. Dessa forma a concepção de formação baseada na politecnia, que se assemelha às ideias da omnilateralidade, ambas pertencendo ao mesmo ambiente de ações educativas, pode subsidiar esse pressuposto.

Sobre politecnia, Ciavatta (2014) teoriza,

Sua origem remota está na educação socialista que pretendia ser omnilateral no sentido de formar o ser humano na sua integralidade física, mental, cultural, política científico-tecnológica. [...] o denso significado da "educação politécnica" como educação omnilateral ou formação em todos os aspectos da vida humana - física, intelectual, estética, moral e para o trabalho, integrando a formação geral e a educação profissional (CIAVATTA, 2014, p. 04).

Esses apontamentos conceituais corroboram as ideias de formação integral do indivíduo, para a formação em sua totalidade, potencializando a educação como ponto de partida para o pleno desenvolvimento do ser social, buscando tangenciar exigências puramente mercadológicas como ponto de chegada. 
Nesse ponto de vista, durante o processo formativo, surge como um meio potencial de transformação de realidades a Educação Profissional e Tecnológica (EPT) integrada à Educação Básica, que, partindo do pressuposto do trabalho como princípio educativo, incita uma formação completa, integral, emancipadora e contra hegemônica. Desta forma, SAVIANI (1989) afirma que o trabalho pode ser considerado como princípio educativo em três sentidos diversos, mas articulados entre si.

Num primeiro sentido, o trabalho é princípio educativo na medida em que determina, pelo grau de desenvolvimento social atingido historicamente, o modo se ser da educação em seu conjunto. Nesse sentido, aos modos de produção [...] correspondem modos distintos de educar com uma correspondente forma dominante de educação. [...]. Num segundo sentido, o trabalho é princípio educativo na medida em que coloca exigências específicas que o processo educativo deve preencher em vista da participação direta dos membros da sociedade no trabalho socialmente produtivo. [...]. Finalmente o trabalho é princípio educativo num terceiro sentido, à medida que determina a educação como uma modalidade específica e diferenciada de trabalho: o trabalho pedagógico (SAVIANI, 1989, p. 1 - 2).

Estando a EPT intimamente relacionada ao trabalho, seus sentidos apontam para a importância dessa ferramenta para a formação emancipadora do cidadão, onde o princípio educativo do trabalho está implícito ao contexto educacional. Ainda mais, o trabalho produzindo a realidade concreta, produz ao mesmo tempo conhecimentos e, desta forma, amplia os horizontes para uma perspectiva de formação completa do sujeito.

A EPT é dada como práxis educativa à medida que auxilia na formação do ser reflexivo, crítico e humanizado, ciente da transformação que pode realizar a partir do trabalho, este encarado não apenas como um meio de subsistência, mas sim, um ícone de transformação da realidade.

Como afirma Freire (1987),

A existência, porque humana, não pode ser muda, silenciosa, nem tampouco pode nutrir se de falsas palavras, mas de palavras verdadeiras, com que os homens transformam o mundo. Existir, humanamente, é pronunciar o mundo, é modificá-lo. O mundo pronunciado, por sua vez, se volta problematizado aos sujeitos pronunciantes, a exigir deles novo pronunciar. Não é no silêncio que os homens se fazem, mas na palavra, no trabalho, na ação-reflexão. Mas, se dizer a palavra verdadeira, que é trabalho, que é práxis, é transformar o mundo, dizer a palavra não é 
privilégio de alguns homens, mas direito de todos os homens. Precisamente por isto, ninguém pode dizer a palavra verdadeira sozinho, ou dizê-la para os outros, num ato de prescrição, com o qual rouba a palavra aos demais (FREIRE, 1987, p. 50).

Concordamos com esse pensamento, no qual, o trabalho é implícito a construção do indivíduo, e nessa perspectiva, a EPT, tornando-se uma aproximação da categoria trabalho no meio educacional, pode corroborar como um instrumento potencializador de transformações sociais.

De acordo com Borges (2017),

Engels (1986) afirma que o trabalho produz o homem e demonstra essa afirmação de forma analítica, considerando, sobretudo, a produção de Darwin. $O$ autor expõe como o homem se diferencia dos outros animais ao ter uma transformação estrutural de sua mão em determinada condição histórica e, a partir daí, o longo caminho até a utilização consciente do gesto - e a teleologia da ação - como trabalho. Esse permite uma ação cada vez mais coletiva e articulada entre os homens, que vai exigir a linguagem, consequentemente, o caminho do desenvolvimento humano na natureza e no mundo humano como ser social (BORGES, 2017, p. 103).

Observa-se o quanto o trabalho está arraigado à construção do ser humano em todas as suas dimensões, sendo parte indissociável do ser social. Com isso, a EPT torna-se essencial no processo formativo que vise a integralidade, a politecnia, o ser reflexivo, crítico e consciente, na transformação de sua realidade.

Entretanto, para que a EPT cumpra essa função é primordial o uso de técnicas e instrumentos que viabilizem sua internalização nos indivíduos inseridos no processo formativo. Tais meios urgem nas práticas pedagógicas e metodologias voltadas a essa modalidade educacional.

\section{METODOLOGIAS UTILIZADAS EM EPT}

A busca por estratégias que ultrapassem a visão tradicional de ensino entra cada vez mais em debate no meio educacional. Essa pesquisa apresentou, através do Estado da Arte, grande parte dos trabalhos apoiados em metodologias alternativas, especialmente, as 
Metodologias Ativas. Com base nos artigos pesquisados, observa-se uma possibilidade de mudança nas metodologias para os próximos anos. É importante considerar que não existem metodologias exclusivas da EPT, mas caminhos que podem ser adaptados às diferentes modalidades de ensino.

A utilização de Metodologias Ativas de ensino-aprendizagem, associadas a técnicas de ensino e estudo, pode apresentar uma ampla possibilidade de alternativas a serem implantadas para a mediação e construção de conhecimentos teóricos, práticos e com significado social, incluindo a realização de pesquisas também em Educação Profissional (MOREIRA; RIBEIRO, 2016), e alavancar uma variedade de métodos a disposição do exercício docente em sala de aula, especialmente, em um contexto de ensino na EPT.

As metodologias ativas de ensino e aprendizagem são relevantes no contexto da educação profissional porque, quando objetivadas, colocam os estudantes como protagonistas de seu processo de ensino e aprendizagem, exigindo mudança de postura acadêmica, dedicação, autonomia e responsabilidade para dar sentido e aplicabilidade social ao que se apreende em sala de aula (MOREIRA; RIBEIRO, 2016, p. 95).

É importante frisar que quando se fala em Metodologias Ativas, fala-se em oferecer, à prática pedagógica, novas perspectivas, atitudes e modos de compartilhar conhecimentos em sala de aula, considerando que, ao se optar por uma metodologia centrada no aluno, estar-se-á, enquanto educador, rompendo com modelos que simplesmente depositam informações e conhecimentos em seus estudantes, distanciando-se, assim, de uma educação bancária (FREIRE, 1996).

Segundo Borges e Alencar (2014), o uso de metodologias ativas implica numa formação crítica dos sujeitos, proporcionando o desenvolvimento da autonomia, criatividade e criticidade, em situações que envolvem o trabalho e tomada de decisões.

Sobre essas considerações, cremos que as Metodologias Ativas surgem para corroborar e potencializar o alcance de uma prática docente voltada para a formação integral e politécnica, defendida nas bases da EPT, podendo se tornar uma ferramenta bastante promissora para o trabalho dos professores inseridos no campo da Educação Profissional. 


\section{DISCUSSÃO SOBRE AS METODOLOGIAS OBSERVADAS NO ESTADO DA ARTE E AS BASES CONCEITUAIS DA EPT}

A formação assistemática, cuja metodologia se desdobra, resumidamente, em um ambiente de aprendizagem que coincide com o próprio espaço produtivo, sob uma didática totalmente instrumental, destoa bastante daquilo que a EPT busca em sua essência: a valorização da integração dos conhecimentos científicos com os conhecimentos inerentes à formação técnica, contribuindo para uma formação ampla do indivíduo, possibilitando a construção de uma consciência capaz de realizar uma leitura crítica do mundo.

Os modelos ainda predominantes de uma educação acrítica e conivente com a simples transmissão de conteúdo, de cunho liberal, terão, ainda mais, dificuldades em conseguirem atender objetivos maiores de uma educação emancipadora. Isso é enfatizado pelos teóricos da EPT e nos artigos pesquisados e analisados ao se trabalhar com o Estado da Arte. Ainda segundo esse levantamento, metodologias inovadoras estão, aos poucos, conquistando espaço e, mesmo com dificuldades, mudando a forma de se conceber o ensino. Suscintamente, o Estado da Arte aponta para um crescente uso das Metodologias Ativas, cuja base centra-se "na aprendizagem colaborativa e na interdisciplinaridade." (CAMARGO; DAROS, 2018, p.16).

É importante considerar que o Parecer do CNE/CEB no 11/2012 traça diretrizes para a EPT, de modo a indicar que essa modalidade de educação poderá propiciar, aos trabalhadores, conhecimentos, saberes e competências que os habilitem a analisar, questionar e entender os fenômenos do cotidiano com mais propriedade, dotando-os também, de capacidade investigativa diante da própria existência a partir de um enfoque que privilegie a criatividade e a criticidade.

De acordo com Borges e Alencar (2014), o uso das Metodologias Ativas alavanca uma formação cidadã crítica e uma formação profissional ampla, proporcionando o desenvolvimento de sujeitos autônomos e capazes de tomar decisões mais acertadas. Daí, percebe-se fortes convergências na concepção formativa da EPT e na utilização das metodologias citadas. 
É possível definir as Metodologias Ativas como aquelas que, ao fazer parte de um processo pedagógico, buscam incentivar os alunos a aprender de forma autônoma e participativa. Dewey (1859-1952), estudioso no campo da educação moderna, há muito já defendia o aluno como centro do processo educativo e a figura do docente como sendo um mediador do processo (DEWEY, 2011).

Ainda que não sejam reconhecidas por essa nomenclatura, muitas práticas docentes podem ser consideradas Metodologias Ativas, pois se concentram no processo de ensino e coloca o aluno como centro nos procedimentos de ensino-aprendizagem. Tal foco é defendido por Freire (1996), ao tratar o processo educativo como algo não realizado por outrem, ou pelo próprio sujeito, mas que se realiza na interação entre sujeitos, por meio de suas palavras, reflexões e ações.

Ao analisar a intenção dos defensores de uma formação cidadã, crítica e integral e a proposta das Metodologias Ativas, ainda que sua concepção destoe, é possível afirmar que Freire (1996) defende um modelo de educação muito similar a elas, quando afirma que, na educação, o que impulsiona a aprendizagem é a superação de desafios, a resolução de problemas e a construção do conhecimento novo a partir de conhecimentos e experiências já existentes nos sujeitos.

\section{CONSIDERAÇÕES FINAIS}

Nesta pesquisa, foi possível constatar como o desenvolvimento de novas tecnologias digitais de informação e comunicação tem influenciado a sociedade e, consequentemente, a educação. Daí a importância de atualização quanto às metodologias, métodos, técnicas e recursos mais apropriados na formação do discente hodierno. O trabalho revela a urgente busca por processos pedagógicos que instiguem o aluno a pensar criticamente e que o transforme num agente ativo na construção do conhecimento, sem diminuir, evidentemente, a importância do docente como mediador e facilitador em um espaço de aprendizagem.

A busca por novas metodologias educacionais eficientes tem, por finalidade, uma formação cidadã, ao introduzir dinamismo e qualidade na construção do saber. 
Através do Estado da Arte realizado, é possível concluir que há tendências sendo construídas, buscando a superação ou se colocando como alternativa ao modelo de educação bancária (FREIRE, 1996). Apesar de as metodologias tradicionais ainda serem bastante utilizadas, aos poucos, tem cedido espaço para outras metodologias, como as ativas, que vislumbram a eficácia na intenção de formar discentes em homens e mulheres emancipados e que tem desmistificado o pressuposto da sala de aula, nos moldes da transmissão de saberes construídos e prontos, instigando-a a ser um lugar cativante e estimulador da produção de conhecimentos. Porém, mesmo com tantos avanços tecnológicos, é perceptível a existência da urgente necessidade no quesito atuação de modo diferente visando ao rompimento da mera transmissão de conceitos e concepções curriculares tradicionais.

Portanto é possível concluir que, apesar das metodologias ativas não terem sido pensadas especificamente para fins de formação cidadã, nos moldes da EPT, quando bem trabalhadas, conseguem esboçar concepções emancipatórias, desperta a autonomia e a capacidade dos discentes tomarem decisões lúcidas. Além disso, elas também suprem a carência por uma metodologia que se utilize de recursos tecnológicos e que fuja às tradicionais pedagogias.

Sem a pretensão de apresentar respostas definitivas para as questões dessa análise, Vale ressaltar que as conclusões apontadas neste estudo são inacabadas e, ao mesmo tempo, fecundas para novas investigações que visem melhorar o processo formativo na EPT.

\section{REFERÊNCIAS}

ALBERTI, T. F. et al. Dinâmicas de grupo orientadas pelas atividades de estudo: desenvolvimento de habilidades e competências na educação profissional. Rev. Bras. Estud. Pedagog. Brasília, v. 95, n. 240, p. 346-362, agosto. 2014. Disponível em: http://www.scielo.br/scielo.php?script=sci_arttext\&pid=S217666812014000200006\&lng=en \&nrm=iso. Acesso em: 15 abr. 2020.

ANDRADE, L. G. da S. B.; FERRETE, R. B. Metodologias Ativas e a Educação Profissional e Tecnológica: invertendo a sala de aula em vista de uma aprendizagem significativa. Educação Profissional e Tecnológica em Revista, v. 3, n² 2, 2019 - Rede Federal de Educação Profissional, Científica e Tecnológica. Disponível em: 
file://C:/Users/MarcosS\%C3\%A9rgio/Downloads/451-Texto\%20do\%20artigo-1559-1-1020191220\%20(8).pdf. Acesso em: 01 mai. 2020.

BARBOSA, E. F.; MOURA, D. G. DE. Metodologias Ativas de Aprendizagem na Educação Profissional e Tecnológica. Boletim Técnico do Senac, 2013.

BARRETO, F. C. Informática descomplicada para educação: aplicações práticas em sala de aula. São Paulo: Érica, 2014.

BELLA, S. R. et al. Metodologias Ativas de Aprendizagem na Educação Profissional. Revista Científica do Centro Universitário de Araras “Dr. Edmundo Ulson”, 2019.

BORGES, L. F. P.. Educação, escola e humanização em Marx, Engels e Lukács. Revista Educação em Questão, v. 55, n. 45, p. 101-126, 2017. Disponível em: https://periodicos.ufrn.br/educacaoemquestao/article/view/12747. Acesso em: 06 fev. 2020.

BORGES, T. S.; ALENCAR, G. Metodologias Ativas na promoção da Formação Crítica do estudante: $O$ uso das Metodologias Ativas como Recurso Didático na Formação Crítica do Estudante do Ensino Superior, 2014. Disponível em: https://pt.scribd.com/document/355929767/08-METODOLOGIAS-ATIVAS-NAPROMOCAODA-FORMACAO-CRITICA-DO-ESTUDANTE-pdf. Acesso em: 02 mar.2020.

BRASIL, Ministério da Educação. Lei Federal n 9.394, de 20 de dezembro de 1996. Estabelece as diretrizes e base da educação nacional - LDB. Disponível em: www.planalto.gov.br. Acesso em: 01 de abril 2020.

BRASIL. Lei (LDB) no 9.394/1996. Lei de Diretrizes e Bases da Educação Nacional. 12a edição. Atualizada em 08/06/2016. Centro de documentação e informação edições Câmara Brasília, 2016. Disponível em: http://www.planalto.gov.br/ccivil_03/leis/19394.htm. Acesso em: 26 fev. 2020.

BRASIL. Resolução da Câmara de Educação Básica do Conselho nacional de Educação no11. Brasília, CEB/2002.

CAMARGO, F.; DAROS, T. A sala de aula inovadora: estratégias pedagógicas para fomentar o aprendizado ativo. Porto Alegre: Penso, 2018.

CIAVATTA, M. O ensino integrado, a politecnia e a educação omnilateral. Por que lutamos? Trabalho \& Educação. Belo Horizonte. v. 23. n.1. p. 187-205. jan-abr. 2014. Disponível em: https://periodicos.ufmg.br/index.php/trabedu/article/view/9303. Acesso em: 03 fev. 2020.

CUNHA, L. A. $O$ ensino profissional na irradiação do industrialismo. São Paulo: Editora UNESP; Brasília, DF: FLACSO, 2000.

DEWEY, J. Experiência e educação. Petrópolis: Vozes, 2011. 
DIESEL, A.; ROOS MARCHESAN, M.; MARTINS, S. N. Metodologias Ativas de Ensino na Sala de Aula: um olhar de docentes da Educação Profissional Técnica de Nível Médio. Revista Signos, [S.I.], v. 37, n. 1, jun. 2016. ISSN 1983-0378. Disponível em:

http://univates.br/revistas/index.php/signos/article/view/1008. Acesso em: 15 abr. 2020.

FERREIRA, N. S. de A. As pesquisas denominadas "estado da arte". Educ. Soc., Campinas, v. 23, n. 79, p. 257-272, Aug. 2002. Disponível em:

http://www.scielo.br/scielo.php?script=sci_arttext\&pid=S0101-

73302002000300013\&lng=en\&nrm=iso. Acesso em: 12 fev. 2020.

FREIRE, P. Pedagogia da autonomia: saberes necessários à prática educativa. 21. ed. São

Paulo: Paz e Terra, 1996. 156 p. (Coleção Leitura).

FREIRE, P. Pedagogia do oprimido, 17ª . ed. Rio de Janeiro, Paz e Terra, 1987.

GIL, A. C. Métodos e técnicas de pesquisa social. 6. ed. São Paulo: Atlas, 2008.

GODOY, A. S. Introdução à Pesquisa Qualitativa e suas Possibilidades. Revista de

Administração de Empresas, v. 35, n. 2, p. 57-63, 1995. Disponível em:

http://www.scielo.br/pdf/rae/v35n2/a08v35n2.pdf. Acesso em: 16 fev. 2020.

ANDRADE, G. da S. B.; FERRETE, R. Metodologias Ativas e a Educação Profissional e Tecnológica. Educação Profissional e Tecnológica em Revista, 2019.

KLEIN, N. A.; AHLERT, E. M. Aprendizagem Baseada em Problemas como Metodologia Ativa na Educação Profissional. Revista Destaques Acadêmicos, [S.I.], v. 11, n. 4, dez. 2020. ISSN 2176-3070. Disponível em:

http://www.univates.br/revistas/index.php/destaques/article/view/2398. Acesso em: 15 abr. 2020.

MACHADO, Y. F.; OLIVEIRA, F. K. de. Orientação Profissional, Gamificação e Educação Profissional e Tecnológica: Uma Revisão Sistemática de Literatura. EPT em Revista, Espírito Santo, v. 3, n. 1, p. 108-126, 06 jul. 2019. Disponível em:

https://ojs2.ifes.edu.br/index.php/ept/article/view/1279/772. Acesso em: 22 abr. 2020.

MANACORDA, M. A. Max e a pedagogia moderna. Campinas, SP: Editora Alínea, 2007.

MARQUES, C. L.; SOUZA, A. M. O uso das TIC na formação para o trabalho: um estudo de caso numa instituição de educação profissional e tecnológica. In: CONGRESO

IBEROAMERICANO DE CIENCIA, TECNOLOGÍA, INNOVACIÓN Y EDUCACIÓN, 1.,2014, Buenos Aires. Anais do Congresso Ibero-americano de Ciência, Tecnologia, Inovação e Educação, 2014. P.1-17. Disponível em:

https://www.oei.es/historico/congreso2014/memoriactei/498.pdf. Acesso em: 22 de abr. 2020.

MOREIRA, J. R.; RIBEIRO, J. B. P. Prática pedagógica baseada em metodologia ativa:

aprendizagem sob a perspectiva do letramento informacional para o ensino na educação 
profissional. Outras Palavras. Brasília, v. 12, n. 2, p. 93-114, 2016. Disponível em: http://revista.faculdadeprojecao.edu.br/index.php/Projecao5/article/view/722. Acesso em: 25 abr. 2020.

MOURA, D. H.; LIMA FILHO, D. L.; SILVA, M. R.. Politecnia e formação integrada: confrontos conceituais, projetos políticos e contradições históricas da educação brasileira. Rev. Bras. Educ. [online]. 2015, vol.20, n.63, pp.1057-1080. Disponível em: http://www.scielo.br/scielo.php?pid=S141324782015000401057\&script=sci_abstract\&tIng= pt. Acesso em: 06 fev. 2020.

PEIXOTO, A. G. O uso de metodologias ativas como ferramenta de potencialização da aprendizagem de diagramas de caso de uso. Outras Palavras, 2016. Disponível em: http://revista.faculdadeprojecao.edu.br/index.php/Projecao5/article/view/718/604. Acesso em: 03 mai.2020.

PEREIRA, R. Método Ativo: Técnicas de Problematização da Realidade aplicada à Educação Básica e ao Ensino Superior. In: VI Colóquio internacional. Educação e Contemporaneidade. São Cristóvão, SE. 20 a 22 setembro de 2012.

RAMOS, M. N. História e política da educação profissional. Curitiba: Instituto Federal do Paraná, 2014. - (Coleção formação pedagógica; v. 5).

SAVIANI, D. Sobre a concepção de politecnia. Rio de Janeiro: Fiocruz; Rio de Janeiro: Escola Politécnica de Saúde Joaquim Venâncio, 1989. 